OPEN ACCESS

Edited by:

Andrea Gomez-Zavaglia, Center for Research and Development in Food Cryotechnology (CIDCA, CONICET), Argentina

Reviewed by: Lucilla lacumin, University of Udine, Italy Marco Rinaldo Oggioni, University of Leicester, United Kingdom

${ }^{*}$ Correspondence: Jiaping $L v$

Ivjp586@vip.sina.com

Specialty section

This article was submitted to

Food Microbiology,

a section of the journal

Frontiers in Microbiology

Received: 13 October 2016 Accepted: 05 July 2017 Published: 19 July 2017

Citation:

Pang X, Zhang S, LU J, Liu L, Ma C,

Yang Y, Ti P, Gao W and Lv J (2017) Identification and Functional Validation

of Autolysis-Associated Genes in

Lactobacillus bulgaricus ATCC

BAA-365. Front. Microbiol. 8:1367.

doi: 10.3389/fmicb.2017.01367

\section{Identification and Functional Validation of Autolysis-Associated Genes in Lactobacillus bulgaricus ATCC BAA-365}

\author{
Xiaoyang Pang ${ }^{1,2}$, Shuwen Zhang ${ }^{1}$, Jing $\mathrm{Lu}^{1}$, Lu Liu ${ }^{1}$, Changlu Ma ${ }^{3}$, Yang Yang ${ }^{1}$, \\ Panpan $T^{1}{ }^{1}$, Weihua $\mathrm{Gao}^{1}$ and Jiaping $L v^{1 *}$ \\ ${ }^{1}$ Key Laboratory of Agro-Food Processing and Quality Control, Institute of Agro-Food Science and Technology, Chinese \\ Academy of Agricultural Science, Beijing, China, ${ }^{2}$ Beijing Advanced Innovation Center for Food Nutrition and Human Health, \\ Beijing Technology and Business University, Beijing, China, ${ }^{3}$ Department of Food and Biological Engineering, Beijing \\ Vocational College of Agriculture, Beijing, China
}

Lactic acid bacteria (LAB) are important organisms in food production. Indeed, LAB autolysis is very critical in dairy processing. For example, it influences the development of cheese flavor by releasing intracellular enzymes, and controls cell growth in yogurts and probiotic products. Two component systems (TCS) constitute essential environmental sensors and effectors of signal transduction in most bacteria. In the present work, mutants of one TCS (LBUL_RS00115/LBUL_RS00110) were generated to assess the relationship between TCS and cell autolysis. The mutants displayed decreased autolysis in comparison with wild type; meanwhile, complementation reversed this effect. The interaction between LBUL_RS00115 and LBUL_RS00110 was confirmed by yeast two-hybrid analysis. These observations suggested that the TCS (LBUL_RS00115/LBUL_RS00110) was involved in autolysis in Lactobacillus delbrueckii subsp. bulgaricus.

Keywords: two component system, autolysis, Lactobacillus delbrueckii, lactic acid bacteria, gene knockout

\section{INTRODUCTION}

Lactic acid bacteria (LAB) are common starters for the production of yogurt and other dairy products, and their autolysis attracts increasing attention (Cibik and Chapot-Chartier, 2000; Ouzari et al., 2002; Ortakci et al., 2015). During the process of cheese production, ripening is critical for its role in determining final product flavor and texture, which constitute the basis for cheese product differentiation (Lazzi et al., 2016). This lengthy procedure (from about 3 weeks to $>2$ years) renders cheese production costly (Sondergaard et al., 2015). Attempts to speed up ripening include temperature increase (Fox et al., 1996), starter culture adjustment (Williams et al., 2006; Garbowska et al., 2015), and enzyme supplementation (Fox et al., 1996). Starter strain lysis in the ripening step releases cytoplasmic enzymes that degrade amino acids into cheese (Xu and Kong, 2013). Such enzymes are believed to promote the degradation of peptides, also removing the bitter ones (Valence et al., 2000; Collins et al., 2003; Visweswaran et al., 2017). It is therefore important to induce LAB starter autolysis during cheese production. While production yogurts, LAB autolysis lowers live cell count of starters (Pang et al., 2014). This demonstrates the significant role of LAB autolysis in food production, and unveiling the underlying mechanisms is of prime importance. 
Bacteria usually sense and react to various changes in their environment via two component systems (TCS) (Cui et al., 2012). TCS are found in most bacteria, primarily as essential environmental sensors and cell signaling effectors (El-Sharoud, 2005; Thevenard et al., 2011; Zuniga et al., 2011). TCS typically consist of a membrane-bound histidine protein kinase (HPK) (sensor) and a soluble response regulator (RR, signaling effector) (El-Sharoud, 2005; Thevenard et al., 2011; Zuniga et al., 2011; Borland et al., 2015).

Genome sequencing predicts multiple TCS in LAB (Thevenard et al., 2011), with many remaining uncharacterized. TCS were shown to be associated with the production of bacteriocins (Roces et al., 2012; Marx et al., 2014). The TCS LBA1524/LBA1525 of L. acidophilus is implicated in acid tolerance (Azcarate-Peril et al., 2005), and LBA1430/LBA1431 in bile tolerance (Pfeiler et al., 2007). The TCS lamBDCA system of Lactobacillus plantarum is likely to affect commensal host-microbe interactions, since a lamA mutant adheres to surfaces (Sturme et al., 2005).
Autolysis of LAB usually occurs at high cell density (Chu et al., 2013; Kovacs et al., 2013; Hong et al., 2014), TCS enable bacteria to sense, respond, and adapt to a wide range of environments, stressors, and growth conditions (Faralla et al., 2014; Straube, 2014; Yu et al., 2014). It has not been confirmed whether there is a correlation between cell autolysis and TCS. The current work aimed to assess the association of TCS and L. bulgaricus cell autolysis by gene knockout techniques. Our findings would provide a strong basis for directional regulation of LAB autolysis.

\section{MATERIALS AND METHODS \\ Bacterial Cultures}

Table 1 lists all strains and plasmids utilized. E. coli and $L$. bulgaricus were cultured in LB and Man-Rogosa-Sharpe (MRS) (Beijing Land Bridge Technology Co., Ltd. CM187), respectively, at $37^{\circ} \mathrm{C}$ with no shaking. Saccharomyces cerevisiae $\mathrm{Y}_{2} \mathrm{HGOLD}$ cells, carrying four reporter genes (HIS3, ADE2, AUR1-C, and

TABLE 1 | Bacterial strains and plasmids used in this study.

\begin{tabular}{|c|c|c|}
\hline Strain or plasmid & Relevant genotype or description & Reference and/or source \\
\hline Strains E. coli DH5 $\alpha$ & $\begin{array}{l}\mathrm{F}^{-}, \text {} 90 \mathrm{~d} \text { lacZ } \triangle \mathrm{M} 15, \Delta(\text { lacZYA-argF }) \cup 169, \text { deoR, recA1, end } A 1, \text { hsdR17 } \\
\left(\mathrm{rk}^{-}, \mathrm{mk}^{+}\right), \text {phoA, supE44, } \lambda^{-}, \text {thi-1, gyrA96, relA1 }\end{array}$ & TaKaRa \\
\hline L. bulgaricus ATCC BAA-365 & Wild-type L. bulgaricus & ATCC \\
\hline L. bulgaricus $\Delta H 4160-1$ & LBUL_RS04160 gene mutant of L. bulgaricus ATCC BAA-365; HPK4160::EryB & This study \\
\hline L. bulgaricus $\Delta \mathrm{HO115-1}$ & LBUL_RS00115 gene mutant of L. bulgaricus ATCC BAA-365; HPK0115::EryB & This study \\
\hline L. bulgaricus rH0115-1 & $\begin{array}{l}\text { Complementation of the LBUL_RS00115 mutant with pMG56e carrying } \\
\text { LBUL_RS00115 gene }\end{array}$ & This study \\
\hline S. cerevisiae $\mathrm{Y}_{2} \mathrm{HGOLD}$ & $\begin{array}{l}\text { the HIS3, ADE2, and MEL1/AUR1-C reporter genes are under the control of } \\
\text { Gal4-responsive promoter elements-G1, G2, and M1 }\end{array}$ & Clontech \\
\hline \multicolumn{3}{|l|}{ Plasmids } \\
\hline pMD18T & clone vector; Ampr & TaKaRa \\
\hline pUC19 & clone vector; $\mathrm{Amp}^{\mathrm{r}}$ & TaKaRa \\
\hline pMG76e & Expression vector of lactic acid bacteria; Em ${ }^{r}$ & $\begin{array}{l}\text { College of food science and Nutritional } \\
\text { Engineering, China Agricultural University }\end{array}$ \\
\hline pMG56e & $\begin{array}{l}\text { Expression vector of lactic acid bacteria; } \mathrm{Cm}^{r} \text {, derivative of pMG36e in which the } \\
\text { gene coding for erythromycin resistance was replaced with a gene coding for } \\
\text { chloramphenicol resistance from pNZ8148 }\end{array}$ & $\begin{array}{l}\text { College of food science and Nutritional } \\
\text { Engineering, China Agricultural University }\end{array}$ \\
\hline pUC19-HPK4160 & $\begin{array}{l}\text { pUC19 derived integration vector containing the LBUL RS04160 gene with Sphl, } \\
\text { EcoRI restriction enzyme sites; Amp }{ }^{r}\end{array}$ & This study \\
\hline pUC19-HPK4160::EryBII & pUC19-HPK4160 derived integration vector containing the EryBll gene; Emr; Amp ${ }^{r}$ & This study \\
\hline pUC19-HPK0115 & $\begin{array}{l}\text { pUC19 derived integration vector containing the LBUL RS00115 gene with Sphl, } \\
\text { EcoRI restriction enzyme sites; Amp }{ }^{r}\end{array}$ & This study \\
\hline pUC19-HPK0115::EryBII & pUC19-HPK0115 derived integration vector containing the EryBll gene; Emr; Ampr & This study \\
\hline pMG56e-HPK0115 & pMG56e derived expression vector carrying full LBUL_RS00115 gene; Cmr & This study \\
\hline pGBKT7 & Plasmid in yeast two-hybrid system; Gal4 (1-147), Trp1, Kan ${ }^{r}$ & Clontech \\
\hline pGADT7 & Plasmid in yeast two-hybrid system; Gal4 (768-881), Leu2, Amp ${ }^{r}$ & Clontech \\
\hline pGBKT7-53 & $\begin{array}{l}\text { Positive control plasmid that encodes a fusion of the murine p53protein (72-390) and } \\
\text { the GAL4 DNA-BD }(1-147)\end{array}$ & Clontech \\
\hline pGBKT7-Lam & Negative control plasmid that encodes the Gal4 BD fused with lamin & Clontech \\
\hline pGADT7-T & $\begin{array}{l}\text { Positive control plasmid that encodes a fusion of the SV40 large T antigen (87-708) } \\
\text { and the GAL4 AD (768-881) }\end{array}$ & Clontech \\
\hline pGBK-HPK0115 & pGBKT7 derived expression vector carrying full LBUL_RS00115 gene; Kan ${ }^{r}$ & This study \\
\hline pGAD-RR0110 & pGADT7 derived expression vector carrying full LBUL_RS00110 gene; Amp ${ }^{r}$ & This study \\
\hline
\end{tabular}


MEL1) controlled by the GAL4 promoter (Xu et al., 2015), were cultured in Yeast Peptone Dextrose ( $10 \mathrm{~g}$ yeast extract, $20 \mathrm{~g}$ peptone, $20 \mathrm{~g}$ dextrose per liter) or synthetic defined (SD) medium (BD Difco Ltd., USA) at $28^{\circ} \mathrm{C}$. Ampicillin (Amp, Sigma Chemical Co, USA), was used for E. coli at $100 \mu \mathrm{g} / \mathrm{mL}$. Erythromycin (Em, Sigma) and Amp were used for L. bulgaricus at $50 \mu \mathrm{g} / \mathrm{mL}$ each. Chloramphenicol was used for L. bulgaricus at $10 \mu \mathrm{g} / \mathrm{mL}$.

\section{Prediction of Two Component System in L. Bulgaricus}

The whole genome sequence of the L. bulgaricus ATCC BAA365 strain was downloaded from NCBI (https://www.ncbi.nlm. nih.gov/nuccore/NC_008529.1), and used for the prediction of TCS. HisKA (PF00512), HATPase-c (PF02518), Response reg (PF00072) from the Protein families database were used in a HMMER search. HisKA.hmm and HATPase-c.hmm were employed for scanning the highly conserved phosphate group binding- and HATPase regions in HPK. Response-reg.hmm was utilized to screen conserved phosphate groups in the response regulator protein.

\section{Construction of Recombinant Plasmids}

To construct a LBUL_RS04160 mutant, a 570 bp fragment intermediate region of the LBUL_RS04160 gene was first amplified by PCR using HPK4160-SphI-F (5'-ACGCGCATGC CGCATGAACTTAAGACGCCC-3') (SphI site underlined) and HPK4160-EcoRI-R (5'-ACATGAATTCTTGCGGCTGTGG CTCTTATC-3') (EcoRI site underlined) primers, and inserted into pUC19 to generate pUC19-HPK4160. The erythromycin resistance gene was amplified by PCR from pMG76e using the EryB-BfaI-F (5'-CCGCTAGATGACCACCGACGCCGCGAC G-3') and EryB-BstEII-R (5'-CGGGTAACCTCACTGCAACCA GGCTTCCGG-3') primers, and inserted into pUC19-HPK4160 to create plasmid pUC19-HPK4160::EryBII (Figure 1).

To construct a LBUL_RS00115 mutant, a 819 bp fragment intermediate region of the LBUL_RS00115 gene was first amplified by PCR with the HPK0115-SphI-F (5'ACGCGCATGCCGCGGGCAGGCAAAAAG-3') (SphI site underlined) and HPK0115-EcoRI-R (5'-ACATGAATTC AACGCAGCGGATGATGCTTA-3') (EcoRI site underlined) primers, and inserted into pUC19 to generate pUC19-HPK0115. The erythromycin resistance gene was amplified by PCR from pMG76e with the EryB-BstEII-F (5'-CGGGTAACCATGACCAC

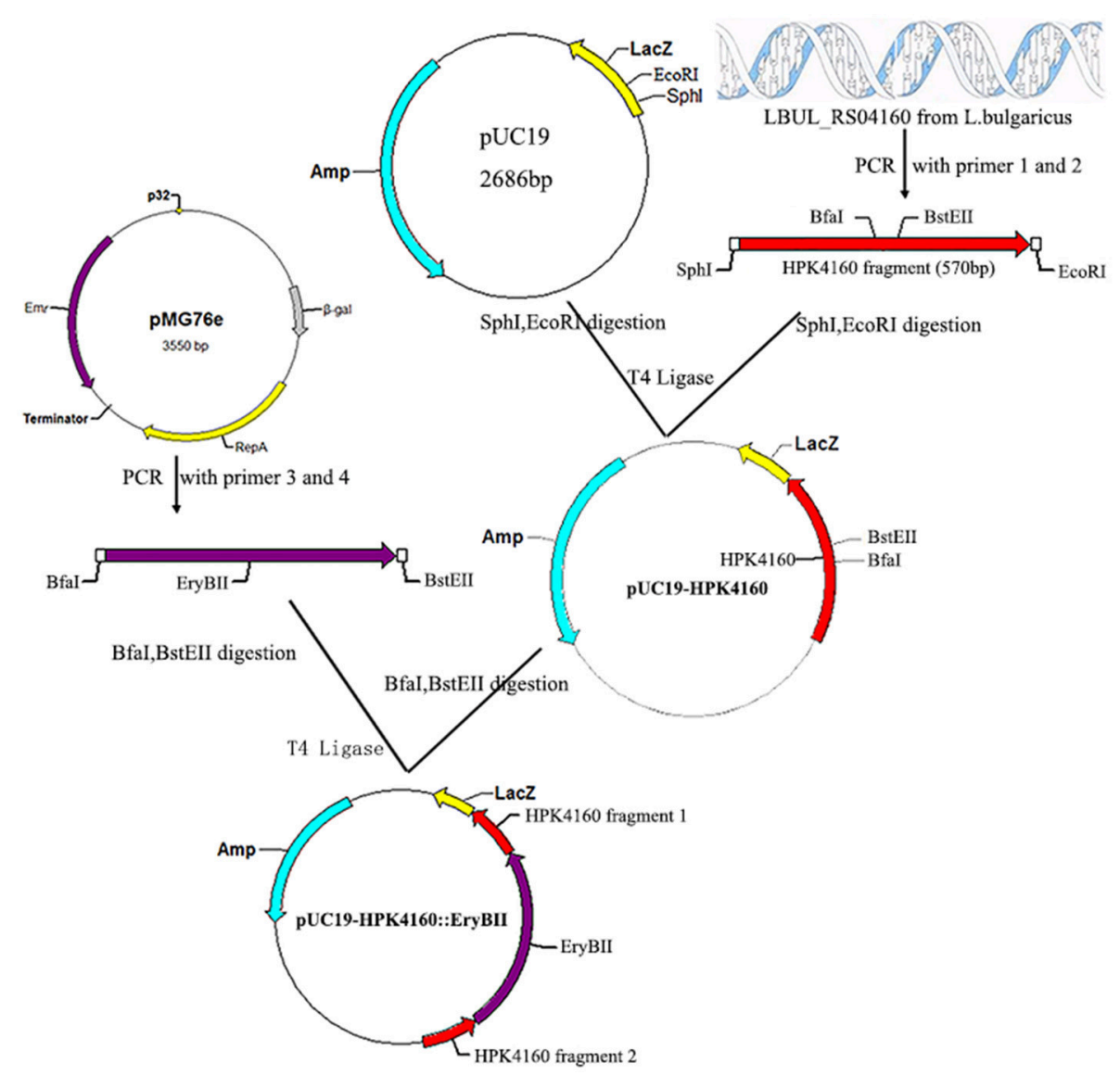

FIGURE 1 | Construction of recombinant plasmid pUC19-HPK4160::EryBll. The red arrow represents the HPK4160 gene from L. bulgaricus ATCC BAA-365; The cyan arrow represents the ampicillin resistance gene; The purple arrow represents the erythromycin resistance gene; Sphl, Ecorl, Bfal, BstEll are four endonuclease hydrolysis sites. 
CGACGCCGCGACG-3') and EryB-BstYI-R (5'-CGAGATCC TCACTGCAACCAGGCTTCCGG-3') primers, and inserted into pUC19-HPK0115 to create the pUC19-HPK0115::EryBII plasmid (Figure 2).

All other gene manipulation experiments were carried out as described previously (Pang et al., 2014).

\section{Transformation of $L$. bulgaricus}

The pUC19-HPK4160::EryBII and pUC19-HPK0115::EryBII plasmids were transformed into L. bulgaricus ATCC BAA-365 as proposed previously (Holo and Nes, 1989; Kim et al., 2009), with minor modifications described in a previous study (Pang et al., 2014).

\section{Complementation of Mutants by the L. bulgaricus LBUL_RS00115 Gene}

A $1.3 \mathrm{~kb}$ fragment, encompassing the complete LBUL_RS00115 coding region was amplified by PCR using the HPK0115-SalI-F (5'-ACGCGTCGACATGATCAACAGCCTGTTCA-3') and HPK0115-SphI-R (5'-ACATGCATGCCTATCCCTTCTGAA TAACT-3') primers from the L. bulgaricus BAA-365 genome, and cloned into pMG56e to generate pMG56e-HPK0115. The latter plasmid (pMG56e-HPK0115) was then introduced into the mutant L. bulgaricus H0115-K7, yielding complemented strain L. bulgaricus H0115-K7-com1 (Table 1). Transformants with successful complementation were selected by culture on $10 \mu \mathrm{g} / \mathrm{mL}$ chloromycetin containing plates.

\section{Autolysis Assessment in LAB}

Bacterial suspension (OD600 $=0.4 \sim 0.6$ ) was centrifuged to remove the bacterial cells, the supernatant was measured OD260/280 $\mathrm{nm}$, the reading was recorded as $A_{0}$. Take the appropriate amount of the above bacterial suspension in the incubator for $\mathrm{t}$ hours. Half of the sample was centrifuged to remove the bacterial cells. Measure the OD260/280 nm of the supernatant and the reading was recorded as $A_{t}$. The remaining bacterial suspension sonicated (400 w, work $3 \mathrm{~s}$, interval $3 \mathrm{~s}$ ) until the solution became clear (the cells are completely broken) under ice-cooling, bacterial cells were removed by centrifugation, measure the OD260/280 nm of the supernatant and the reading was recorded as $A_{s}$. The autolysis rate is calculated according to the formula:

$$
\text { Autolysis rate } / \%=\left(\mathrm{A}_{\mathrm{t}}-\mathrm{A}_{0}\right) /\left(\mathrm{A}_{\mathrm{s}}-\mathrm{A}_{0}\right) * 100 \%
$$

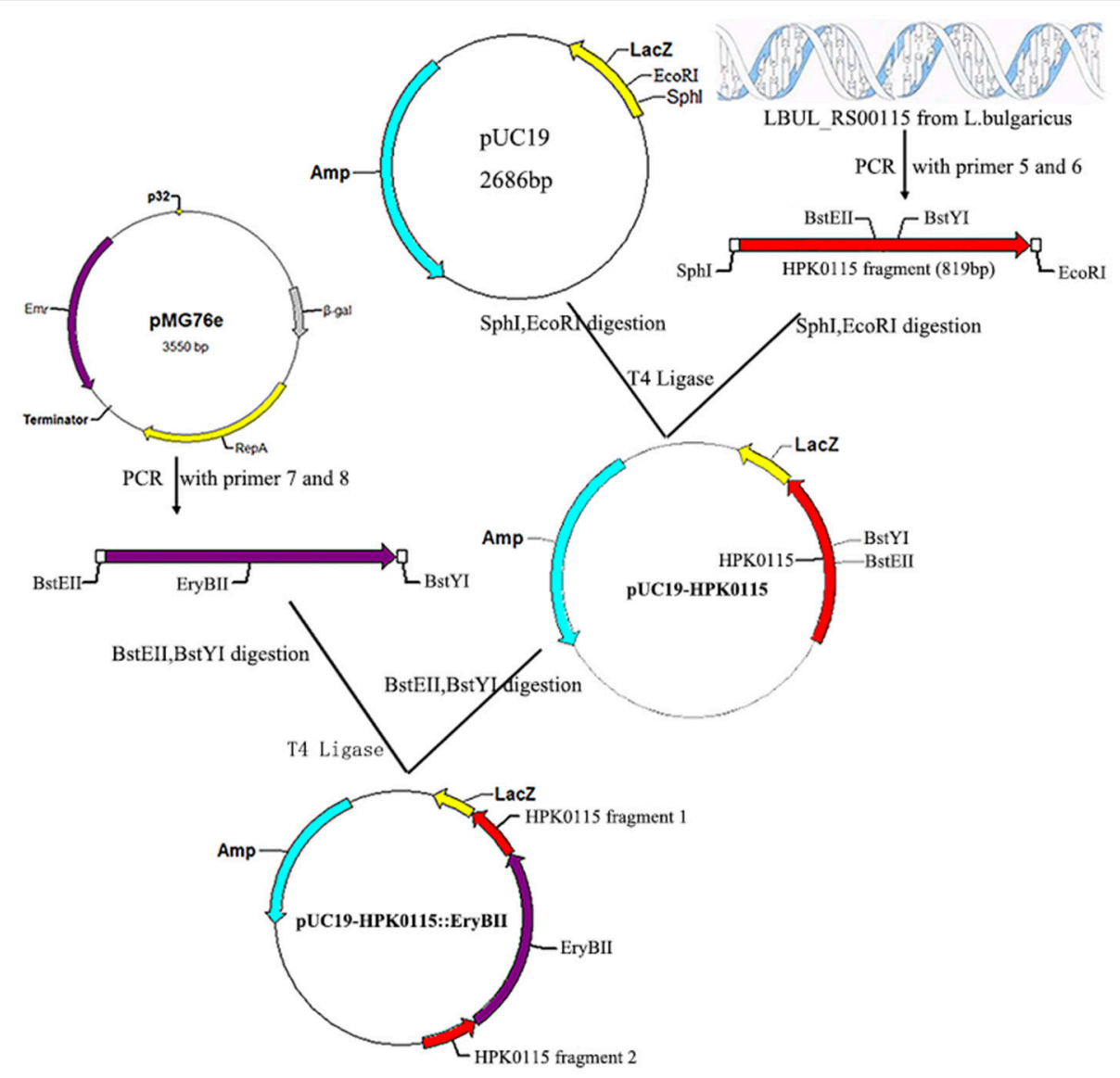

FIGURE 2 | Construction of recombinant plasmid pUC19-HPK0115::EryBII. The red arrow represents the HPK0115 gene fragment from L. bulgaricus ATCC BAA-365; The cyan arrow represents the ampicillin resistance gene; The purple arrow represents the erythromycin resistance gene; Sphl, Ecorl, BstEll, BstYl are four endonuclease hydrolysis sites. 
Groups were compared by One-Way ANOVA and LSD test.

\section{Yeast Two-Hybrid Analysis between WP_011677872.1 and WP_011677871.1}

It is difficult to construct a two hybrid system by using full length WP_011677872.1 and WP_011677871.1 genes, because WP_011677872.1 contain six transmembrane regions. Therefore, these transmembrane regions of WP_011677872.1 were removed, and the HATPase-c domain of WP_011677872.1 was selected as the bait protein. The WP_011677872.1 HATPasec domain gene was PCR amplified with the HATPase-NdeI-F (5'-GGAATTCCATATGATGGTAAATATCGTAAGCAT CA-3') and HATPase-BamHI-R (5'-CGGGATCCCTATCC CTTCTGAATAACT- $3^{\prime}$ ) primers, and inserted into the pGBKT7 vector (Clontech), to create the two-hybrid plasmid pGBK-HPK0115 (Figure 3); the complete LBUL_RS00110 sequence was amplified by PCR using the RR0110- NdeI-F (5'-GGAATTCCATATGATGCTAGCCATCATCATTT- ${ }^{\prime}$ )

and RR0110-BamHI-R (5'-CGGGATCCTTAAACAAGGTC ATTTT-3') primers, and inserted into the pGADT7 vector (Clontech), to create the two-hybrid plasmid pGAD-RR0110 (Figure 4).

Co-transformation of $S$. cerevisiae $\mathrm{Y}_{2} \mathrm{HGOLD}$ was carried out using various two-hybrid plasmid pairs: pGBK-HPK0115/pGAD-RR0110 (0.15 $\mu \mathrm{g} / \mathrm{each})$, pGBKT753/pGADT7-T (positive control), pGBKT7-Lam/ pGADT7-T (negative control). $\mathrm{Y}_{2} \mathrm{HGold}$ cell amounts were determined with (His) or without (-His) histidine, to assess HIS3 reporter activation, which in combination with AUR1-C reporter activation (growth on $0.1 \mathrm{mg} / \mathrm{mL}$ aureobasidin A, Clontech), reflects protein interaction. Strain $S$. cerevisiae $\mathrm{Y}_{2} \mathrm{HGold}$, and

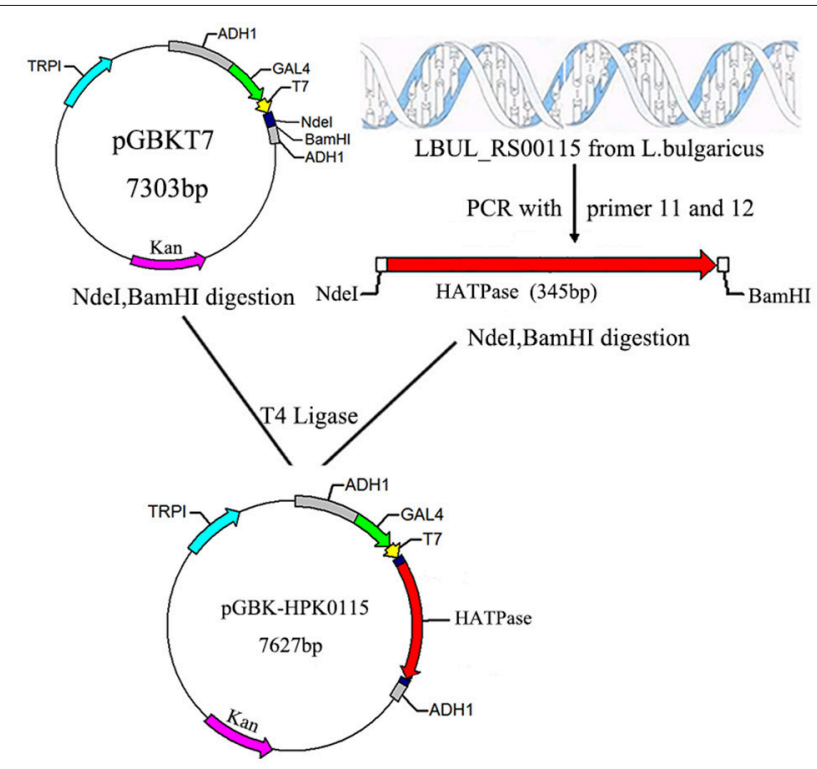

FIGURE 3 | Construction of recombinant plasmid pGBK-HPK0115. The red arrow represents the LBUL_RS00115 gene fragment from $L$. bulgaricus ATCC BAA-365; The magenta arrow represents the kanamycin resistance gene; $\mathrm{Ndel}, \mathrm{BamHI}$ are endonuclease hydrolysis sites. various vectors were obtained from Clontech Laboratories, Inc.

\section{RESULTS}

\section{TCS Distribution in L. bulgaricus BAA-365}

The whole genome sequence of $L$. bulgaricus BAA-365 was scanned by the Hmmer software for HisKA, HATPase-c and Response-reg domains. A total of 7 HPKs and 7 RRs were identified, as shown in Table 2. NCBI BLASTP was used for HPK and RR function prediction: the functions of five RRs have been reported, while those of the two remaining RRs remain unknown. The structural domains of WP_011543855.1, WP_003620064.1, WP_011677872.1, and WP_011677871.1 were assessed by utilizing Simple Modular Architecture Research Tool (SMART) (Figure 5).

Two histidine protein kinases, WP_011543855.1 and WP_011677872.1, had transmembrane regions (blue block), which can directly sense changes in the external environment. The PAS domain (PER-ARNTSIM domain) can sense changes of light, oxygen, redox potential, small molecule ligand and total cell energy, and is an important signal receptor domain (Furukawa-Hibi et al., 2015; Guo et al., 2015; Kasai et al., 2015). Compared with the structural regions of WP_011543855.1 and WP_011677872.1, those of WP_003620064.1 and WP_011677871.1 were relatively simple; both genes contained typical signal receiving domains (REC), and WP_011677871.1 contained a LytTR type signal output domain. In order to verify whether there is a correlation between the two TCS and cell autolysis, LBUL_RS04160 (coding gene of WP_011543855.1) and LBUL_RS00115 (coding gene of WP_011677872.1) were knocked out, respectively.

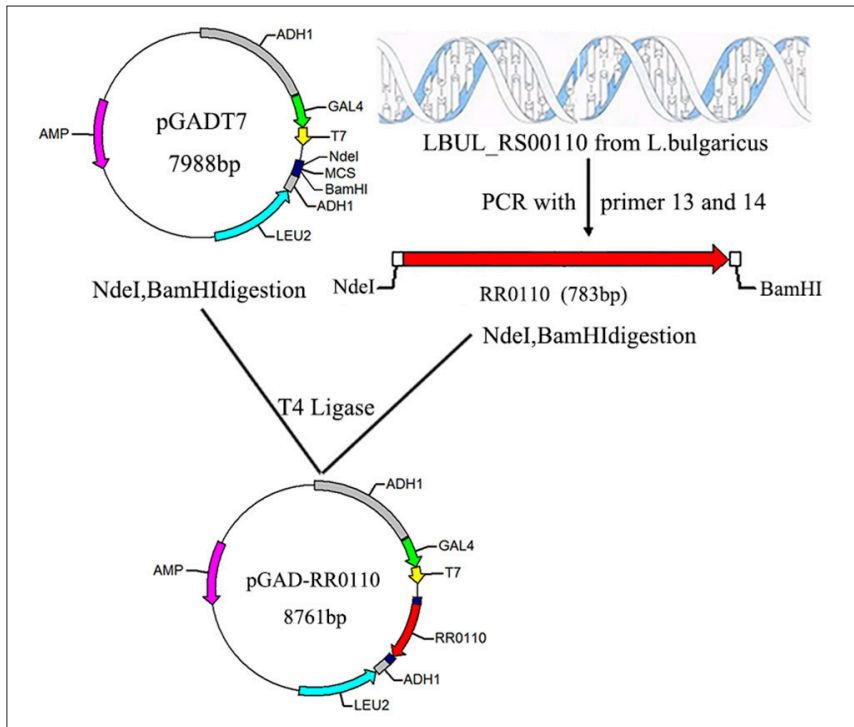

FIGURE 4 | Construction of recombinant plasmid pGAD-RR0110. The red arrow represents the LBUL_RS00110 gene fragment from $L$. bulgaricus ATCC BAA-365; The magenta arrow represents the ampicillin resistance gene; Ndel, $\mathrm{BamHI}$ are endonuclease hydrolysis sites. 
TABLE 2 | Functional prediction of L. bulgaricus BAA-365 TCS system.

\begin{tabular}{|c|c|c|c|c|}
\hline HK protein no. & RR protein no. & HK/RR order & Sequence homology (HK/RR, Identities/Identities) & Function prediction \\
\hline WP_011678182.1 & WP_011678181.1 & $\mathrm{RH}$ & YP_194286/YP_194287 44\%/67\% L.aci & Bile tolerance \\
\hline WP_011677912.1 & WP_003620636.1 & $\mathrm{RH}$ & NP_814923/NP_814922 49\%/75\% E.fae & Vancomycin resistance \\
\hline WP_011543754.1 & WP_003613569.1 & $\mathrm{RH}$ & WP_011374912.1MP_011374913.142\%/66\% L.sak & Anaerobic regulation \\
\hline WP_011678447.1 & WP_003618182.1 & $H R$ & YP_194374/YP_194375 62\%/91\% L.aci & Protein hydrolysis, Acid resistance \\
\hline WP_003621126.1 & WP_003624707.1 & $H R$ & WP_011373988.1MP_011373987.155\%/82\% L.sak & Vancomycin resistance, Anaerobic regulation \\
\hline WP_011543855.1 & WP_003620064.1 & $\mathrm{RH}$ & WP_005726711.1MP_060785076.1 95\%/87\% L.cri & Unknown \\
\hline WP_011677872.1 & WP_011677871.1 & $\mathrm{RH}$ & WP_009557837.1/WP_009557836.183\%/88\% L.equ & Unknown \\
\hline
\end{tabular}

L.aci, Lactobacillus acidophilus; Efae, Enterococcus faecalis; L.sak, Lactobacillus sakei; L.cri, Lactobacillus crispatus; L.equ, Lactobacillus equicursoris.
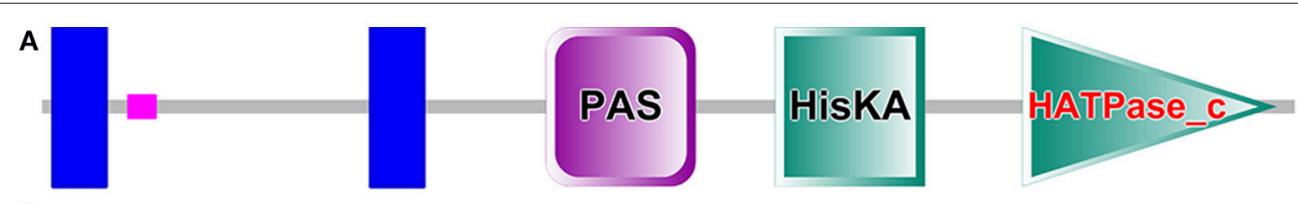

B

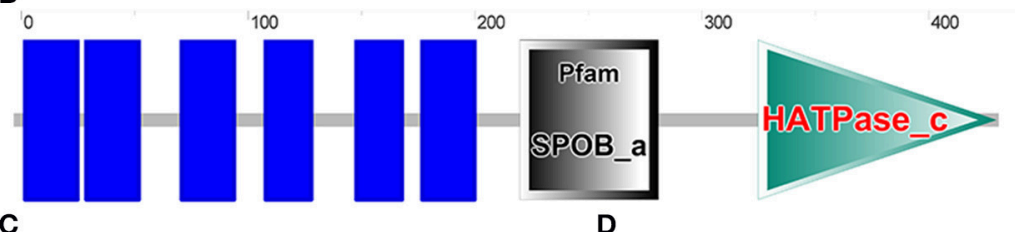

C

200

D
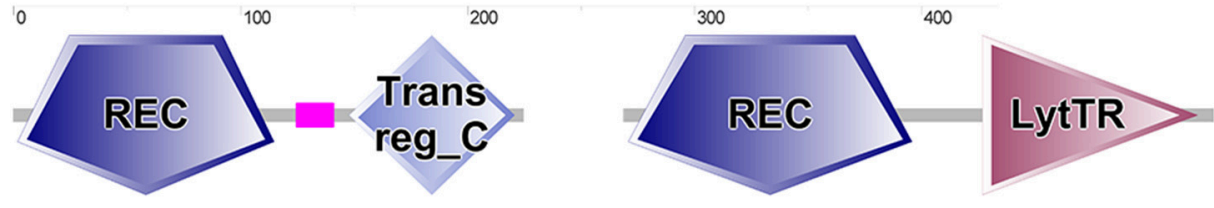

100

200

0

100

200

FIGURE 5 | Results of SMART analysis of four proteins. (A). WP_011543855.1 (Encoded by LBUL_RS04160, CDS Region in Nucleotide: $811449-813107)$; (B) WP_011677872.1 (Encoded by LBUL_RS00115, CDS Region in Nucleotide: 23723-25027); (C) WP_003620064.1 (Encoded by LBUL_RS04155, CDS Region in Nucleotide: 810772-811448); (D) WP_011677871.1 (Encoded by LBUL_RS00110, CDS Region in Nucleotide: 22935-23717).

\section{Identification of the Recombinant Plasmids pUC19-HPK4160::EryBII and pUC19-HPK0115::EryBII}

The recombinant plasmids pUC19-HPK4160::EryBII obtained from transformed E. coli DH5 $\alpha$ were submitted to digestion by SphI and EcoRI. Electrophoresis data indicated the presence of both the $4.4 \mathrm{kbp}$ pUC19HPK4160::EryBII and $1.7 \mathrm{kbp}$ HPK4160::EryBII fragments, suggesting successful insertion of EryBII into pUC19HPK4160. In agreement, PCR reactions using Primers 1 and 2 (Table 3) showed concordant data (Figure 6). Next, pUC19-HPK0115::EryBII identification was carried out in a similar way to pUC19-HPK4160::EryBII. After digestion, the 4.7 kb pUC19-HPK0115::EryBII and $2.0 \mathrm{~kb}$ HPK0115::EryBII fragments were all present, also suggesting successful HPK0115::EryBII insertion into the pUC19 vector. These findings were confirmed by PCR using Primers 5 and 6 (Figure 6).

\section{Screening and Identification of Mutant Strains}

The recombinant plasmids pUC19-HPK4160::EryBII and pUC19-HPK0115::EryBII were transformed into L. bulgaricus ATCC BAA-365, respectively, by electroporation. After culture for $2 \mathrm{~h}$ at $37^{\circ} \mathrm{C}$, the transformed bacteria were transferred on solid MRS medium with $0.5 \mathrm{M}$ sucrose and erythromycin (50 $\mu \mathrm{g} / \mathrm{mL}$ ) for selection. Next, candidate colonies were plated onto MRS agar with ampicillin $(50 \mu \mathrm{g} / \mathrm{mL})$. The double-crossover mutant bacteria could not grow in the latter conditions. Finally, three mutants L. bulgaricus $\triangle H 4160$ 1-3 with pUC19HPK4160::EryBII and one double-crossover mutant L. bulgaricus $\triangle H 01151$ with pUC19-HPK0115:: EryBII were chosen in the second round.

DNA was obtained from the $L$. bulgaricus $\Delta \mathrm{H} 4160-1$ and wildtype BAA-365 genomes, after $24 \mathrm{~h}$ of culture in MRS broth, and amplified by PCR with Primers 1 and 2 . This yielded 0.5 and $1.7 \mathrm{~kb}$ amplicons from wildtype and 
TABLE 3 | Primers used in this study.

\begin{tabular}{|c|c|c|c|}
\hline No. & Primer & Sequence $\left(5^{\prime}-3^{\prime}\right)$ & Reference \\
\hline 1 & HPK4160-Sphl-F & ACGCGCATGCCGCATGAACTTAAGACGCCC & This study \\
\hline 2 & HPK4160-EcoRI-R & ACATGAATTCTTGCGGCTGTGGCTCTTATC & This study \\
\hline 3 & EryB-Bfal-F & CCGCTAGATGACCACCGACGCCGCGACG & This study \\
\hline 4 & EryB-BstEll-R & CGGGTAACCTCACTGCAACCAGGCTTCCGG & This study \\
\hline 5 & HPK0115-Sphl-F & ACGCGCATGCCGCGGGCAGGCAAAAAG & This study \\
\hline 6 & HPK0115-EcoRI-R & ACATGAATTCAACGCAGCGGATGATGCTTA & This study \\
\hline 7 & EryB-BstEll-F & CGGGTAACCATGACCACCGACGCCGCGACG & This study \\
\hline 8 & EryB-BstYI-R & CGAGATCCTCACTGCAACCAGGCTTCCGG & This study \\
\hline 9 & HPK0115-Sall-F & ACGCGTCGACATGATCAACAGCCTGTTC & This study \\
\hline 10 & HPK0115-Sphl-R & ACATGCATGCCTATCCCTTCTGAATAACT & This study \\
\hline 11 & HATPase-Ndel-F & GGAATTCCATATGATGGTAAATATCGTAAGCATCA & This study \\
\hline 12 & HATPase-BamHI-R & CGGGATCCCTATCCCTTCTGAATAACT & This study \\
\hline 13 & RR0110-Ndel-F & GGAATTCCATATGATGCTAGCCATCATCATIT & This study \\
\hline 14 & RR0110-BamHI-R & CGGGATCCTTAAACAAGGTCATIT & This study \\
\hline
\end{tabular}

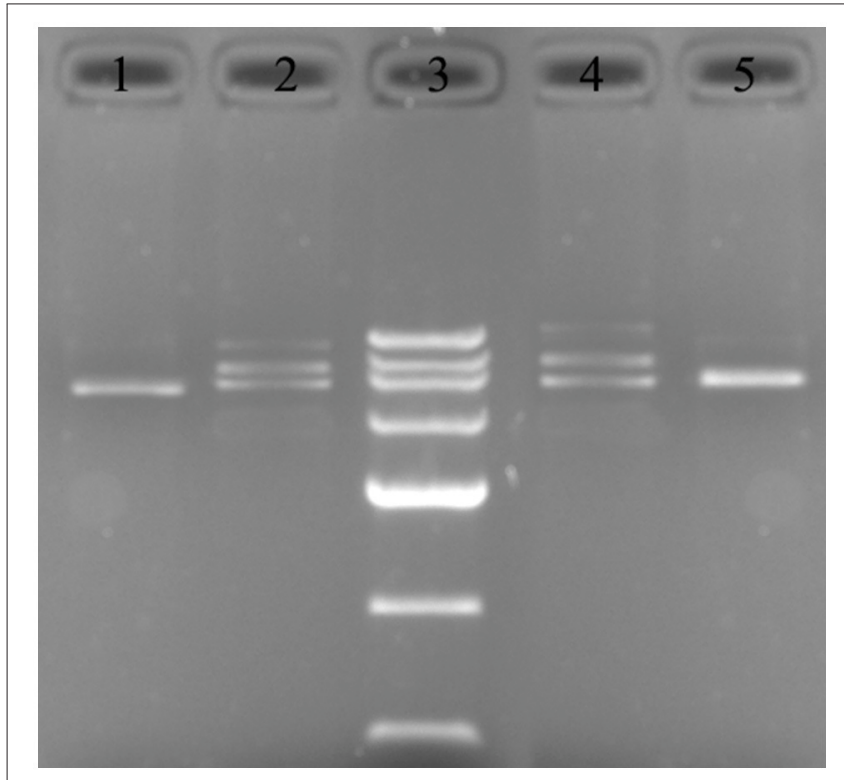

FIGURE 6 | Recombinant plasmid mapping. 1: PCR detection of the HPK4160::EryBll gene from pUC19-HPK4160::EryBll using Primers 1 and 2; 2: pUC19-HPK4160::EryBll was cut by Sphl and EcoRI to 4.4, 2.7, $1.7 \mathrm{kbp}$ fragments; 3: DNA marker III (200, 500, 800, 1,200, 2,000, 3,000, 4,500 bp); 4: pUC19-HPK0115::EryBll was cut by Sph I and ECORI to 4.7, 2.7, $2.0 \mathrm{kbp}$ fragments. 5: PCR detection of the HPK0115::EryBll gene from pUC19-HPK0115::EryBll using Primers 5 and 6.

mutant genomic DNAs, respectively (Figure 7); the $\sim 1.2 \mathrm{~kb}$ difference reflected the inserted erythromycin resistance gene. These data confirmed successful LBUL_RS04160 knockout by inserting the erythromycin resistance gene. The identification of LBUL_RS00115 mutant L. bulgaricus $\Delta \mathrm{H} 0115-1$ was carried out as described above (Figure 7).

For complementation, pMG56e-HPK0115 was transformed into L. bulgaricus $\triangle H 0115-1$ by electroporation. The HPK0115complemented strain was named $\mathrm{r} \Delta \mathrm{H} 0115-1$. As shown in

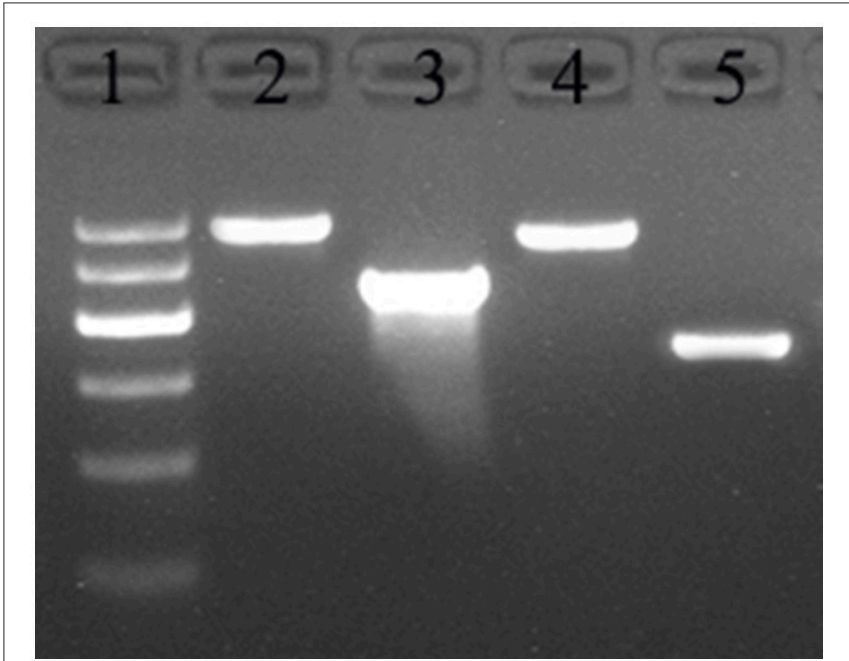

FIGURE 7 | Detection of HPK gene knockout $L$. bulgaricus. 1: DNA marker D2000 (100, 250, 500, 750, 1,000, 2,000); 2: PCR with Primers 5 and 6 from mutant $\triangle H 0115-1$ genome; 3: PCR with Primers 5 and 6 from BAA-365 genome; 4: PCR with Primers 1 and 2 from mutant $\triangle H 4160-1$ genome; 5: PCR with Primers 1 and 2 from BAA-365 genome.

Figure 8D, r $\Delta \mathrm{H} 0115-1$ autolysis was markedly increased in comparison with that of $\Delta H 0115-1$, with no significant difference compared with that of wild type. These findings suggested that HPK0115 complementation restituted the autolytic capacity.

\section{Autolysis Assessment Data}

In BAA-365, $\Delta \mathrm{H} 4160-1, \Delta \mathrm{H} 0115-1$, and $\mathrm{r} \Delta \mathrm{H} 0115-1$, autolysis monitoring results revealed no significant differences between the LBUL_RS04160 gene knockout strain $\Delta \mathrm{H} 4160-1$ and wide type strain BAA-365; this indicated that LBUL_RS04160 gene was not associated with cell autolysis. However, autolysis rate of the LBUL_RS00115 gene knockout strain $\Delta \mathrm{H} 0115-1$ was 
starkly reduced compared with the value obtained for the wild type strain at the $16 \mathrm{~h}$ time point. In addition, a markedly enhanced maximum OD value was obtained in the knockout mutant compared with wild type; this indicated that the density of $L$. bulgaricus population was significantly increased when the LBUL_RS00115 gene was knocked out (Figure 8). In order to further demonstrate that the autolysis of $\Delta \mathrm{H} 0115-1$ changed significantly, we monitored the colony counts of the four strains at different time points, the results shows that when the bacteria grown to stationary phase, the viable count of $\Delta \mathrm{H} 0115-1$ is significantly higher than that of other bacteria (Figure 9). The four bacteria grown to $24 \mathrm{~h}$ were observed by electron microscopy, it can be seen only $\Delta \mathrm{H} 0115-1$ bacterial cell wall is still relatively complete, but the other three strains of cell wall can
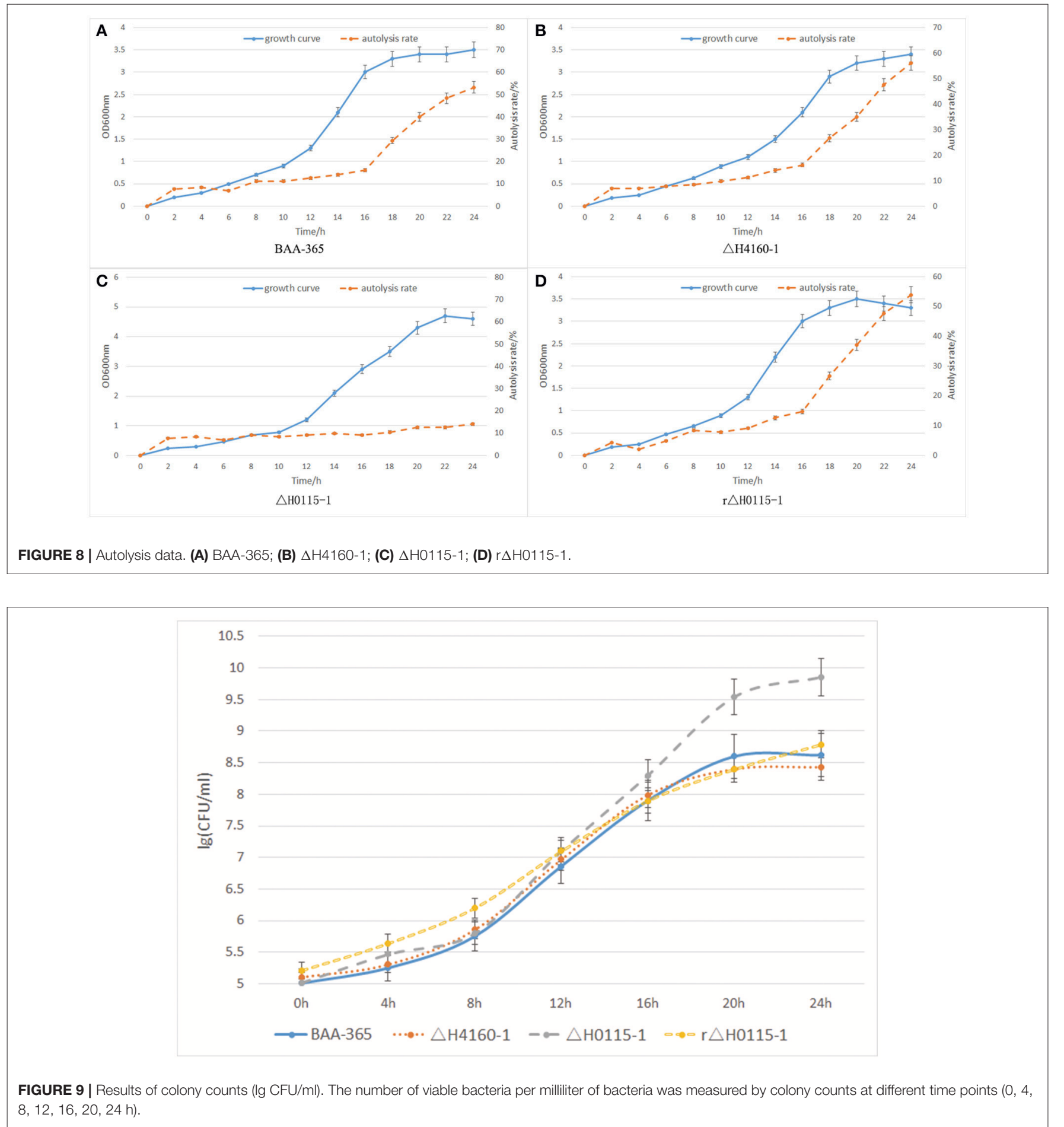
be seen obvious damage (Figure 10). These findings indicated a significant function for LBUL_RS00115 in L. bulgaricus autolysis. Meanwhile, a reduced autolysis remained in LBUL_RS00115 knockout organisms, implying the contribution of additional genes the autolytic process in L. bulgaricus.

\section{Two-Hybrid Analysis Results between WP_011677872.1 and WP_011677871.1}

The yeast two-hybrid system represents a well-known method in identifying protein interactions (Chini, 2014; Ferro et al., 2014). To determine whether the WP_011677872.1 (encoded by LBUL_RS00115) and WP_011677871.1 (encoded by LBUL_RS00110) proteins interact, two-hybrid system plasmids were generated with the HATPase-c domain gene of LBUL_RS00115 and full LBUL_RS00110 gene. The two-hybrid plasmids pGBK-HPK0115 and pGAD-RR0110 were cotransformed into $S$. cerevisiae $\mathrm{Y}_{2}$ HGOLD. The cotransformants could grow on SD/-Trp-Leu-His plates with $0.1 \mathrm{mg} \cdot \mathrm{mL}^{-1}$ aureobasidin A (Clontech) (Figure 11). These data demonstrated that these cotransformants activated both
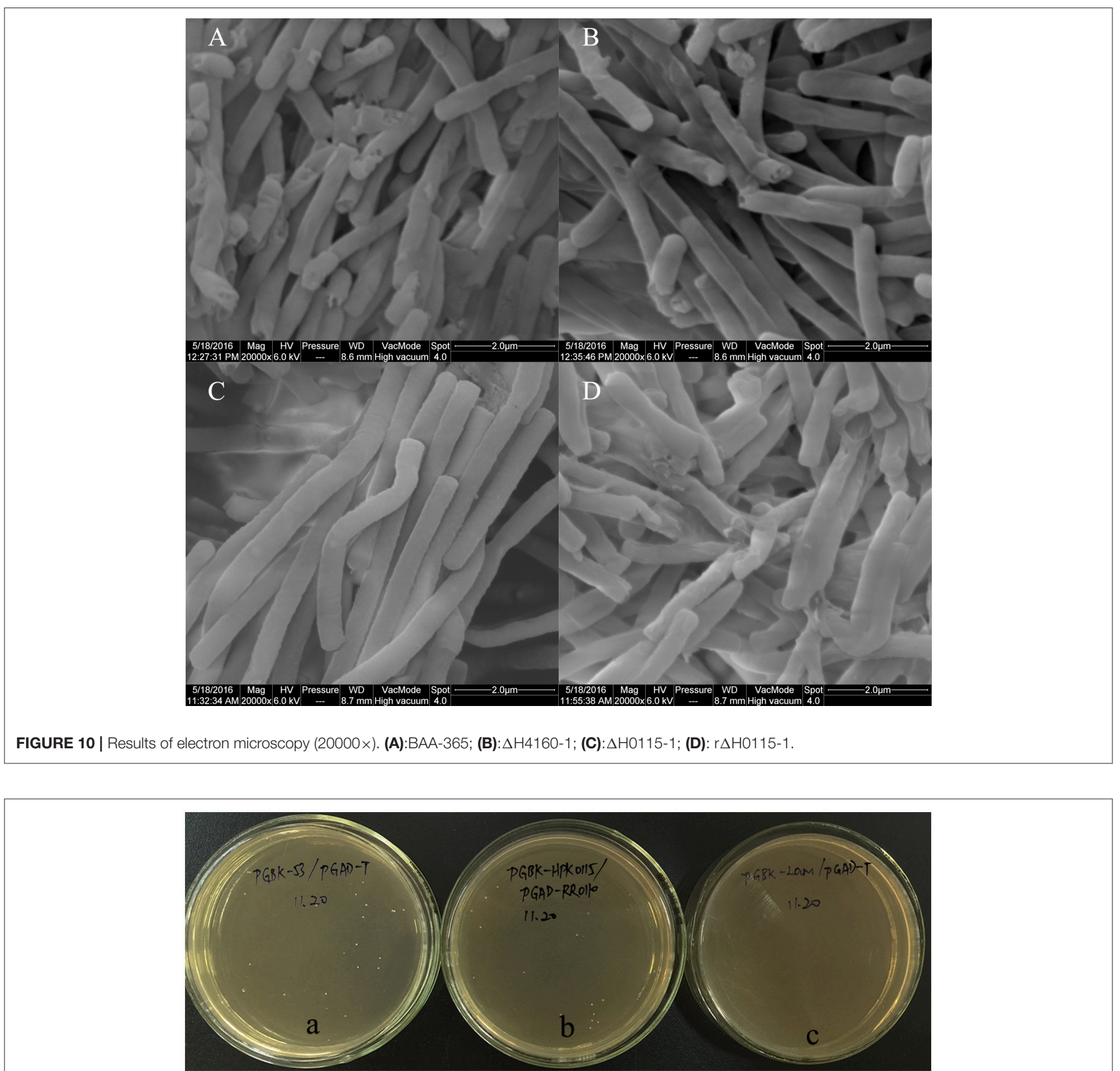

FIGURE 11 | WP_011677872.1 and WP_011677871.1 interaction in a yeast two-hybrid assay. (a) pGBKT7-53/pGADT7-T; (b) pGBK-HPK0115/pGAD-RR0110; (c) pGBKT7-Lam/pGADT7-T. 
HIS3 and AUR1-C reporters, confirming interaction occurrence between WP_011677872.1 and WP_011677871.1.

\section{DISCUSSION}

The autolytic ability of LAB is essential for their use in food industry (Visweswaran et al., 2013). Previous research in our laboratory demonstrated that $\mathrm{N}$-acetylmuramidase has a critical function in L. bulgaricus autolysis (Pang et al., 2014), as one of the major degraders of the cell wall. However, we are more interested in which protein transfer autolysis signals to $\mathrm{N}$ acetylmuramidase. TCS are bacterial components that sense the surrounding environment (Marchadier and Hetherington, 2014; Yu et al., 2014), and LAB autolysis usually occurs at high cell density. It remains unclear whether there is a correlation between cell autolysis and TCS. In this study, the genes of two TCS whose functions are unknown were knocked out, respectively; results showed that autolysis rates were markedly lower for the LBUL_RS00115 gene mutant in comparison with the wild type strain BAA-365, which suggested that LBUL_RS00115 (coding gene of WP_011677872.1) contributes to L. bulgaricus autolysis. Furthermore, we found a direct interaction, including a phosphorelay, between WP_011677872.1 and WP_011677871.1 in this study. The interaction was characterized by yeast twohybrid analysis. The above results demonstrated that the TCS WP_011677872.1/WP_011677871.1 is related to cell autolysis in

\section{REFERENCES}

Azcarate-Peril, M. A., Mcauliffe, O., Altermann, E., Lick, S., Russell, W. M., and Klaenhammer, T. R. (2005). Microarray analysis of a twocomponent regulatory system involved in acid resistance and proteolytic activity in Lactobacillus acidophilus. Appl. Environ. Microbiol. 71, 5794-5804. doi: 10.1128/AEM.71.10.5794-5804.2005

Borland, S., Oudart, A., Prigent-Combaret, C., Brochier-Armanet, C., and Wisniewski-Dye, F. (2015). Genome-wide survey of two-component signal transduction systems in the plant growth-promoting bacterium Azospirillum. BMC Genomics 16:833. doi: 10.1186/s12864-015-1962-x

Chini, A. (2014). Application of yeast-two hybrid assay to chemical genomic screens: a high-throughput system to identify novel molecules modulating plant hormone receptor complexes. Methods Mol. Biol. 1056, 35-43. doi: 10.1007/978-1-62703-592-7_4

Chu, X., Xia, R., He, N., and Fang, Y. (2013). Role of Rot in bacterial autolysis regulation of Staphylococcus aureus NCTC8325. Res. Microbiol. 164, 695-700. doi: 10.1016/j.resmic.2013.06.001

Cibik, R., and Chapot-Chartier, M. P. (2000). Autolysis of dairy leuconostocs and detection of peptidoglycan hydrolases by renaturing SDS-PAGE. J. Appl. Microbiol. 89, 862-869. doi: 10.1046/j.1365-2672.2000.01191.x

Collins, Y. F., Mcsweeney, P. L., and Wilkinson, M. G. (2003). Evidence of a relationship between autolysis of starter bacteria and lipolysis in cheddar cheese during ripening. J. Dairy Res. 70, 105-113. doi: 10.1017/S0022029902005915

Cui, Y., Liu, W., Qu, X., Chen, Z., Zhang, X., Liu, T., et al. (2012). A two component system is involved in acid adaptation of Lactobacillus delbrueckii subsp. bulgaricus. Microbiol. Res. 167, 253-261. doi: 10.1016/j.micres.2011.11.003

El-Sharoud, W. M. (2005). Two-component signal transduction systems as key players in stress responses of lactic acid bacteria. Sci. Prog. 88, 203-228. doi: 10.3184/003685005783238381

Faralla, C., Metruccio, M. M., De Chiara, M., Mu, R., Patras, K. A., Muzzi, A., et al. (2014). Analysis of two-component systems in group B Streptococcus shows that RgfAC and the novel FspSR modulate virulence and bacterial fitness. MBio 5, e00870-e00814. doi: 10.1128/mBio.00870-14
L. bulgaricus, confirming our previous assumptions. However, whether the response regulator of this TCS can directly regulate the $\mathrm{N}$-acetylmuramidase gene needs to be further investigated. The regulatory system of WP_011677872.1/WP_011677871.1 in L. bulgaricus could be a novel target for controlling cell autolysis. $\mathrm{N}$-acetylmuramidase is involved in other metabolic processes in vivo, such as bacterial division, less impact on bacteria is produced by regulating TCS than $\mathrm{N}$-acetylmuramidase. This study provides new insights for understanding autolysis regulation in L. bulgaricus.

\section{AUTHOR CONTRIBUTIONS}

$\mathrm{XP}$ and JLv contributed in study conception and experimental design. YY and LL carried out vector construction experiments. SZ carried out Two-hybrid analysis experiments. XP and CM wrote the manuscript. PT and WG carried out the autolysis detection experiments. All authors have read and approved of the manuscript.

\section{ACKNOWLEDGMENTS}

We thank ZADY for checking the English grammar. The authors are grateful for the financial support provided by the National Natural Science Foundation of China (No.31471603).

Ferro, E., Baldini, E., and Trabalzini, L. (2014). Use of the yeast two-hybrid technology to isolate molecular interactions of Ras GTPases. Methods Mol. Biol. 1120, 97-120. doi: 10.1007/978-1-62703-791-4_7

Fox, P. F., Wallace, J. M., Morgan, S., Lynch, C. M., Niland, E. J., and Tobin, J. (1996). Acceleration of cheese ripening. Antonie Van Leeuwenhoek 70, 271-297. doi: 10.1007/BF00395937

Furukawa-Hibi, Y., Nagai, T., Yun, J., and Yamada, K. (2015). Stress increases DNA methylation of the neuronal PAS domain 4 (Npas4) gene. Neuroreport 26, 827-832. doi: 10.1097/WNR.0000000000000430

Garbowska, M., Pluta, A., and Berthold-Pluta, A. (2015). Dipeptidase activity and growth of heat-treated commercial dairy starter culture. Appl. Biochem. Biotechnol. 175, 2602-2615. doi: 10.1007/s12010-014-1453-6

Guo, L. I., Zhang, J., Jin, J., Gao, X., Yu, J., Geng, Q., et al. (2015). Genetic variants of endothelial PAS domain protein 1 are associated with susceptibility to acute mountain sickness in individuals unaccustomed to high altitude: a nested case-control study. Exp. Ther. Med. 10, 907-914. doi: 10.3892/etm.2015.2611

Holo, H., and Nes, I. F. (1989). High-frequency transformation, by electroporation, of Lactococcus lactis subsp. cremoris grown with glycine in osmotically stabilized media. Appl. Environ. Microbiol. 55, 3119-3123.

Hong, W., Khampang, P., Erbe, C., Kumar, S., Taylor, S. R., and Kerschner, J. E. (2014). Nontypeable Haemophilus influenzae inhibits autolysis and fratricide of Streptococcus pneumoniae in vitro. Microbes Infect. 16, 203-213. doi: 10.1016/j.micinf.2013.11.006

Kasai, S., Torii, S., Kakita, A., and Sogawa, K. (2015). Inhibitory PAS domain protein is a substrate of PINK1 and Parkin and mediates cell death in a Parkinson's disease model. Cell Death Dis. 6:e1886. doi: 10.1038/cddis.2015.243

Kim, S. J., Lee, J. Y., Jun, D. Y., Song, J. Y., Lee, W. K., Cho, M. J., et al. (2009). Oral administration of Lactococcus lactis expressing Helicobacter pylori Cag7-ct383 protein induces systemic anti-Cag7 immune response in mice. FEMS Immunol. Med. Microbiol. 57, 257-268. doi: 10.1111/j.1574-695X.2009.00605.x

Kovacs, Z., Szarka, M., Kovacs, S., Boczonadi, I., Emri, T., Abe, K., et al. (2013). Effect of cell wall integrity stress and RlmA transcription factor on asexual development and autolysis in Aspergillus nidulans. Fungal Genet. Biol. 54, 1-14. doi: 10.1016/j.fgb.2013.02.004 
Lazzi, C., Povolo, M., Locci, F., Bernini, V., Neviani, E., and Gatti, M. (2016). Can the development and autolysis of lactic acid bacteria influence the cheese volatile fraction? The case of Grana Padano. Int. J. Food Microbiol. 233, 20-28. doi: 10.1016/j.ijfoodmicro.2016.06.009

Marchadier, E., and Hetherington, A. M. (2014). Involvement of two-component signalling systems in the regulation of stomatal aperture by light in Arabidopsis thaliana. New Phytol. 203, 462-468. doi: 10.1111/nph.12813

Marx, P., Meiers, M., and Bruckner, R. (2014). Activity of the response regulator CiaR in mutants of Streptococcus pneumoniae R6 altered in acetyl phosphate production. Front. Microbiol. 5:772. doi: 10.3389/fmicb.2014.00772

Ortakci, F., Broadbent, J. R., Oberg, C. J., and Mcmahon, D. J. (2015). Late blowing of Cheddar cheese induced by accelerated ripening and ribose and galactose supplementation in presence of a novel obligatory heterofermentative nonstarter Lactobacillus wasatchensis. J. Dairy Sci. 98, 7460-7472. doi: 10.3168/jds.2015-9468

Ouzari, H., Cherif, A., and Mora, D. (2002). Autolytic phenotype of Lactococcus lactis strains isolated from traditional Tunisian dairy products. J. Appl. Microbiol. 92, 812-820. doi: 10.1046/j.1365-2672.2002.01585.x

Pang, X., Cui, W., Liu, L., Zhang, S., and Lv, J. (2014). Gene knockout and overexpression analysis revealed the role of $\mathrm{N}$-acetylmuramidase in autolysis of Lactobacillus delbrueckii subsp. bulgaricus ljj-6. PLOS ONE 9:e104829. doi: 10.1371/journal.pone.0104829

Pfeiler, E. A., Azcarate-Peril, M. A., and Klaenhammer, T. R. (2007), Characterization of a novel bile-inducible operon encoding a two-component regulatory system in Lactobacillus acidophilus. J. Bacteriol. 189, 4624-4634. doi: 10.1128/JB.00337-07

Roces, C., Courtin, P., Kulakauskas, S., Rodriguez, A., Chapot-Chartier, M. P., and Martinez, B. (2012). Isolation of Lactococcus lactis mutants simultaneously resistant to the cell wall-active bacteriocin Lcn972, lysozyme, nisin, and bacteriophage c2. Appl. Environ. Microbiol. 78, 4157-4163. doi: 10.1128/AEM.00795-12

Sondergaard, L., Ryssel, M., Svendsen, C., Hoier, E., Andersen, U., Hammershoj, M., et al. (2015). Impact of $\mathrm{NaCl}$ reduction in Danish semi-hard Samsoe cheeses on proliferation and autolysis of DL-starter cultures. Int. J. Food Microbiol. 213, 59-70. doi: 10.1016/j.ijfoodmicro.2015.06.031

Straube, R. (2014). Reciprocal regulation as a source of ultrasensitivity in twocomponent systems with a bifunctional sensor kinase. PLoS Comput. Biol. 10:e1003614. doi: 10.1371/journal.pcbi.1003614

Sturme, M. H., Nakayama, J., Molenaar, D., Murakami, Y., Kunugi, R., Fujii, T., et al. (2005). An agr-like two-component regulatory system in Lactobacillus plantarum is involved in production of a novel cyclic peptide and regulation of adherence. J. Bacteriol. 187, 5224-5235. doi: 10.1128/JB.187.15.52245235.2005

Thevenard, B., Rasoava, N., Fourcassie, P., Monnet, V., Boyaval, P., and Rul, F. (2011). Characterization of Streptococcus thermophilus two-component systems: in silico analysis, functional analysis and expression of response regulator genes in pure or mixed culture with its yogurt partner, Lactobacillus delbrueckii subsp. bulgaricus. Int. J. Food Microbiol. 151, 171-181. doi: 10.1016/j.ijfoodmicro.2011.08.019

Valence, F., Deutsch, S. M., Richoux, R., Gagnaire, V., and Lortal, S. (2000). Autolysis and related proteolysis in Swiss cheese for two Lactobacillus helveticus strains. J. Dairy Res. 67, 261-271. doi: 10.1017/S0022029900004118

Visweswaran, G. R., Kurek, D., Szeliga, M., Pastrana, F. R., Kuipers, O. P., Kok, J., et al. (2017). Expression of prophage-encoded endolysins contributes to autolysis of Lactococcus lactis. Appl. Microbiol. Biotechnol. 101, 1099-1110. doi: 10.1007/s00253-016-7822-z

Visweswaran, G. R., Steen, A., Leenhouts, K., Szeliga, M., Ruban, B., HesselingMeinders, A., et al. (2013). AcmD, a homolog of the major autolysin AcmA of Lactococcus lactis, binds to the cell wall and contributes to cell separation and autolysis. PLoS ONE 8:e72167. doi: 10.1371/journal.pone.0072167

Williams, A. G., Withers, S. E., Brechany, E. Y., and Banks, J. M. (2006). Glutamate dehydrogenase activity in lactobacilli and the use of glutamate dehydrogenase-producing adjunct Lactobacillus spp. cultures in the manufacture of cheddar cheese. J. Appl. Microbiol. 101, 1062-1075. doi: 10.1111/j.1365-2672.2006.03017.x

$\mathrm{Xu}, \mathrm{Y}$., and Kong, J. (2013). Construction and potential application of controlled autolytic systems for Lactobacillus casei in cheese manufacture. J. Food Prot. 76, 1187-1193. doi: 10.4315/0362-028X.JFP-12-307

Xu, Y., Zhang, Z., Lu, Y., Zhang, L., Li, P., and Jia, R. (2015). Construction and identification of the bait vector containing duck circovirus cap gene for the yeast two-hybrid system. Bing Du Xue Bao 31, 282-286. doi: 10.13242/j.cnki.bingduxuebao.002697

Yu, S., Peng, Y., Chen, W., Deng, Y., and Guo, Y. (2014). Comparative genomic analysis of two-component signal transduction systems in probiotic Lactobacillus casei. Indian J. Microbiol. 54, 293-301. doi: 10.1007/s12088-014-0456-x

Zuniga, M., Gomez-Escoin, C. L., and Gonzalez-Candelas, F. (2011). Evolutionary history of the OmpR/IIIA family of signal transduction two component systems in Lactobacillaceae and Leuconostocaceae. BMC Evol. Biol. 11:34. doi: 10.1186/1471-2148-11-34

Conflict of Interest Statement: The authors declare that the research was conducted in the absence of any commercial or financial relationships that could be construed as a potential conflict of interest.

Copyright (c) 2017 Pang, Zhang, Lu, Liu, Ma, Yang, Ti, Gao and Lv. This is an open-access article distributed under the terms of the Creative Commons Attribution License (CC BY). The use, distribution or reproduction in other forums is permitted, provided the original author(s) or licensor are credited and that the original publication in this journal is cited, in accordance with accepted academic practice. No use, distribution or reproduction is permitted which does not comply with these terms. 